\title{
Electrochemical and Surface Morphological Studies of Carbon Steel Corrosion by a Novel Polynuclear Schiff Base in HCl Solution
}

\author{
K. S. Shaju, K. Joby Thomas, Vinod P. Raphael, and Aby Paul \\ Research Division, Department of Chemistry, St. Thomas' College, University of Calicut, Thrissur, Kerala 680 001, India
}

Correspondence should be addressed to K. Joby Thomas; drjobythomask@gmail.com

Received 3 September 2013; Accepted 2 October 2013

Academic Editors: X. R. Nóvoa and Q. Qu

Copyright $(2013$ K. S. Shaju et al. This is an open access article distributed under the Creative Commons Attribution License, which permits unrestricted use, distribution, and reproduction in any medium, provided the original work is properly cited.

\begin{abstract}
The corrosion inhibition efficiency of a potential polynuclear Schiff base, (s)-2-(anthracene-9 (10H)-ylidene amino)-5guanidinopentanoic acid (A9Y5GPA), on carbon steel (CS) in $1 \mathrm{M}$ hydrochloric acid solution has been investigated using weight loss measurements, electrochemical impedance spectroscopy (EIS), and potentiodynamic polarization studies. The corrosion inhibition efficiencies of parent amine [(s)-2-amino-5-guanidinopentanoic acid] and parent ketone (anthracene-9 (10H)-one) on carbon steel in $1.0 \mathrm{M}$ hydrochloric acid solution have also been investigated using weight loss studies. The electrochemical and weight loss data established that the inhibition efficiency on CS increases with the increase in the concentration of inhibitor, A9Y5GPA. The adsorption of A9Y5GPA obeys the Langmuir adsorption isotherm. Thermodynamic parameters $\left(K_{\mathrm{ads}}, \Delta G_{\mathrm{ads}}^{0}\right)$ were calculated using the adsorption isotherm. Activation parameters of the corrosion process $\left(E_{a}, \Delta H^{*}\right.$ and $\left.\Delta S^{*}\right)$ were also calculated from the corrosion rates obtained from temperature studies. Tafel plot analysis revealed that A9Y5GPA acts as a mixed-type inhibitor. A probable inhibition mechanism was also proposed. Surface morphology of the carbon steel specimens in the presence and absence of the inhibitor was evaluated by SEM analysis.
\end{abstract}

\section{Introduction}

The use of hydrochloric acid in metal industries for acid pickling, descaling, and cleaning process is the major reason for the increase in the dissolution rate of carbon steel. The use of certain organic compounds as inhibitors is the most practical method to prevent corrosion of the carbon steel (CS) in acidic media [1-3]. Compounds with $\pi$-bonds generally exhibit good inhibitive properties due to interaction of $\pi$ orbital with the metal surface [4]. Schiff bases are organic molecules possessing azomethine linkage and many of them act as effective potential corrosion inhibitors [5-8]. Increasing efforts have been made to study the corrosion behavior of metals and mechanism of inhibition during the past decade mainly through electrochemical investigations [9-11]. The present investigation was undertaken to examine the corrosion inhibition behavior of a novel polynuclear Schiff base (A9Y5GPA) derived from anthracene-9 (10H)-one and (s)-2amino-5-guanidinopentanoic acid in $1 \mathrm{M} \mathrm{HCl}$ solution on CS at different temperatures. The study was performed by weight loss measurements, electrochemical impedance spectroscopy (EIS), and potentiodynamic polarization analysis.

\section{Experimental}

2.1. Inhibitor. Polynuclear Schiff base (A9Y5GPA) was obtained by the condensation of equimolar mixture of anthracene-9 (10H)-one and (s)-2-amino-5-guanidinopentanoic acid in ethanol. The reaction mixture was refluxed for 5 hours, cooled by keeping overnight to obtain dark-coloured compound, filtered, washed, and dried. Figure 1 shows the molecular structure of polynuclear Schiff base A9Y5GPA. Anal.calcd for $\mathrm{C}_{20} \mathrm{H}_{22} \mathrm{~N}_{4} \mathrm{O}_{2}$ : C, 68.49; $\mathrm{H}, 6.28 ; \mathrm{N}, 15.98 \%$. Found. C, 67.86; H, 7.24; N, 15.64\%; m.p. $=235^{\circ} \mathrm{C}$; IR (KBr): $v_{\mathrm{C}=\mathrm{N}}=1591 \mathrm{~cm}^{-1}, v_{\mathrm{COOH}}=3067 \mathrm{~cm}^{-1}, \delta_{\mathrm{NH} 2}=3431 \mathrm{~cm}^{-1}$ (doublet), $\nu_{\mathrm{NH}}=3,304 \mathrm{~cm}^{-1} .{ }^{1} \mathrm{Hnmr}: \quad \delta_{\mathrm{COOH}} 12.21$, 


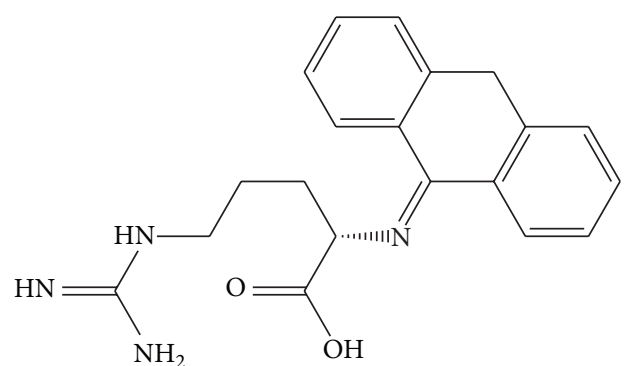

Figure 1: Molecular structure of A9Y5GPA.

$\delta_{\mathrm{NH} 2}=6.32, \delta_{\mathrm{CNH}}=7.54 .{ }^{13} \mathrm{Cnmr}: \delta_{\mathrm{COOH}}=174.6$, $\delta_{\mathrm{C}=\mathrm{N}}=151.5, \delta_{\mathrm{CNH}}=156.2 \mathrm{ppm}$.

2.2. Solutions. The aggressive solution of $1 \mathrm{M} \mathrm{HCl}$ was prepared by dilution of A.R grade $37 \%$ of $\mathrm{HCl}$ (Merck) with deionized water. Inhibitor solutions were prepared in the range, $0.2 \mathrm{mM}-1.0 \mathrm{mM}$ concentrations.

2.3. Weight Loss Measurements. Mild steel specimens of dimension $1.5 \times 2 \times 0.1 \mathrm{~cm}$ were cut and abraded with various grades of silicon carbide papers $(200,400,600,800$, 1000,1200 , and 2000). The chemical composition of CS specimens was determined by EDX analysis and found to be (approx.) C, 0.5\%; Mn, 0.07\%; P, 0.02\%; S, 0.015\%; Si, 0.02\% and rest Fe. The exact area and thickness of each coupon were measured and washed with soap water. Specimens were then degreased again with acetone and finally dried. After weighing, specimens were immersed in $50 \mathrm{~mL}$ acid solutions (naturally aerated) at $30-60^{\circ} \mathrm{C}$ in the absence and presence of the inhibitor (A9Y5GPA) using hooks and fishing lines. Weight loss of metal specimens was noted after $24 \mathrm{~h}$. The experiments were carried out in duplicate and the average values were reported. The corrosion rate $(\nu)$ and the percentage of inhibition efficiency $\left(\eta_{w} \%\right)$ were calculated by the following equations $[12,13]$ :

$$
\begin{gathered}
\nu=\frac{W}{S t}, \\
\eta_{w} \%=\frac{v_{0}-v}{v_{0}} \times 100,
\end{gathered}
$$

where $W$ is the weight loss ( $\mathrm{g}$ ) of specimen, $S$ is the total area $\left(\mathrm{cm}^{2}\right)$ of specimens, $t$ is the time of treatment $(24 \mathrm{~h})$, and $v_{0}$ and $v$ are the corrosion rates $\left(\mathrm{mmy}^{-1}\right)$ of uninhibited and inhibited specimens, respectively.

2.4. Electrochemical Impedance Spectroscopy (EIS). The EIS measurements were performed in a three-electrode cell assembly. Saturated calomel electrode (SCE) was used as the reference electrode. Platinum electrode having $1 \mathrm{~cm}^{2}$ area was taken as counter electrode. Metal specimens with an exposed area of $1 \mathrm{~cm}^{2}$ were used as the working electrode. The EIS experiments were carried out on an Ivium compactstat-e electrochemical system. $1 \mathrm{M} \mathrm{HCl}$ (no stirring) was taken as the electrolyte and the working area of the metal specimens was exposed to the electrolyte for $1 \mathrm{~h}$ prior to the measurement. EIS measurements were performed at constant potential (OCP) in the frequency range from $1 \mathrm{KHz}$ to $100 \mathrm{mHz}$ with amplitude of $10 \mathrm{mV}$ as excitation signal. The percentage of inhibitions from impedance measurements was calculated using charge transfer resistance values by the following expression [14]:

$$
\eta_{\mathrm{EIS}} \%=\frac{R_{\mathrm{ct}}-R_{\mathrm{ct}}^{\prime}}{R_{\mathrm{ct}}} \times 100,
$$

where $R_{\mathrm{ct}}$ and $R_{\mathrm{ct}}^{\prime}$ are the charge transfer resistance of working electrode with and without inhibitor, respectively.

2.5. Potentiodynamic Polarization Studies. Electrochemical polarization studies on CS specimens in $1 \mathrm{M} \mathrm{HCl}$ with and without inhibitor were performed by recording anodic and cathodic potentiodynamic polarization curves. Polarization plots were obtained in the electrode potential range from -100 to $+100 \mathrm{mV}$ versus equilibrium potential $\left(E_{\text {corr }}\right)$ at a scan rate of $1 \mathrm{mV} / \mathrm{sec}$. Tafel polarization analysis was done by extrapolating anodic and cathodic curves to obtain corrosion current densities $\left(I_{\text {corr }}\right)$. The percentage of inhibition efficiency $\left(\eta_{\text {pol }} \%\right)$ was evaluated from the measured $I_{\text {corr }}$ values using the following relation [15]:

$$
\eta_{\text {pol }} \%=\frac{I_{\text {corr }}-I_{\text {corr }}^{\prime}}{I_{\text {corr }}} \times 100,
$$

where $I_{\text {corr }}$ and $I_{\text {corr }}^{\prime}$ are the corrosion current densities of the exposed area of the working electrode in the absence and presence of inhibitor, respectively.

From the slope analysis of the linear polarization curves in the vicinity of corrosion potential of blank and different concentrations of the inhibitor, the values of polarization resistance $\left(R_{p}\right)$ in $1 \mathrm{M} \mathrm{HCl}$ solution were obtained. From the evaluated polarization resistance, the inhibition efficiency was calculated using the relationship

$$
\eta_{R_{p}} \%=\frac{R_{p}^{\prime}-R_{p}}{R_{p}^{\prime}} \times 100,
$$

where $R_{p}^{\prime}$ and $R_{p}$ are the polarization resistance in the presence and absence of inhibitor, respectively [16].

2.6. Scanning Electron Microscopy. Surface analyses were performed using scanning electron microscope (model: Hitachi SU6600). SEM images were obtained from CS surface after the immersion in $1 \mathrm{MHCl}$ solutions in the absence and presence of the inhibitor A9Y5GPA $(1 \mathrm{mM})$ for $24 \mathrm{~h}$ at $30^{\circ} \mathrm{C}$.

\section{Results and Discussion}

3.1. Weight Loss Measurements. Weight loss of CS specimens in $1 \mathrm{M} \mathrm{HCl}$ at $30^{\circ} \mathrm{C}$ was determined at $24 \mathrm{~h}$ in the presence of various concentrations of inhibitor (A9Y5GPA). The corrosion rates, inhibition efficiencies, and surface coverage $(\theta)$ 
TABLE 1: The corrosion rate, percentage of inhibition efficiency, and surface coverage for $\mathrm{CS}$ specimens immersed in $1 \mathrm{M} \mathrm{HCl}$ at $30^{\circ} \mathrm{C}$ for $24 \mathrm{~h}$ in the presence and absence of A9Y5GPA.

\begin{tabular}{lccc}
\hline$C(\mathrm{mM})$ & $\begin{array}{c}\text { Corrosion } \\
\text { rate }\left(\mathrm{mmy}^{-1}\right)\end{array}$ & $\begin{array}{c}\text { Inhibition } \\
\text { efficiency }\left(\eta_{W} \%\right)\end{array}$ & $\theta$ \\
\hline 0 & 6.503 & - & - \\
0.2 & 3.440 & 47.09 & 0.47 \\
0.4 & 2.906 & 55.31 & 0.55 \\
0.6 & 2.382 & 63.37 & 0.63 \\
0.8 & 1.969 & 69.72 & 0.70 \\
1.0 & 1.723 & 73.50 & 0.74 \\
\hline
\end{tabular}

in the presence of inhibitor for CS specimens for the period of $24 \mathrm{~h}$ are shown in the Table 1. Data clearly established that the corrosion rate markedly decreased with inhibitor concentration from 0 to $0.2 \mathrm{mM}$. Beyond this concentration, corrosion rate showed a gradual decrease. This response is due to the fact that the surface coverage $(\theta)$ of the inhibitor molecules on the metal through adsorption increases with the increase in concentration. At the inhibitor concentration of $1.0 \mathrm{mM}$, the maximum $\eta_{w} \%$ was 73.50 , which shows that A9Y5GPA acts as good corrosion inhibitor for CS in $\mathrm{HCl}$.

3.2. Comparison of Inhibition Efficiency of Schiff Base with Its Parent Compounds. To compare the inhibition efficiencies of Schiff base, parent ketone (anthracene-9 (10H)-one), and parent amine [(s)-2-amino-5-guanidinopentanoic acid], weight loss measurements of CS specimens were performed in $1 \mathrm{M} \mathrm{HCl}$ at $30^{\circ} \mathrm{C}$. The percentage of corrosion inhibition efficiencies obtained for Schiff base, parent ketone, and parent amine on CS is represented in Figure 2. The inhibition efficiency of the Schiff base A9Y5GPA was markedly higher than that of parent ketone and parent amine for the studied concentrations. This investigation clearly establishes the role of azomethine linkage $(\mathrm{C}=\mathrm{N})$ present in the Schiff base which actively participates in the corrosion inhibition mechanism.

\subsection{Adsorption Isotherm and Free Energy of Adsorption.}

The mechanism of adsorption and the surface behavior of organic molecules can be easily viewed through adsorption isotherms. Different models of adsorption isotherms considered are Langmuir, Temkin, Frumkin, and Freundlich isotherms. For the evaluation of thermodynamic parameters, it is necessary to determine the best fit isotherm with the aid of correlation coefficient $\left(R^{2}\right)$. Among the isotherms mentioned above, the best description of the adsorption behavior of A9Y5GPA on CS specimens in $1 \mathrm{MHCl}$ was Langmuir adsorption isotherm and the model is expressed as follows [17]:

$$
\frac{C}{\theta}=\frac{1}{K_{\mathrm{ads}}}+C
$$

where $C$ is the concentration of the inhibitor, $\theta$ is the fractional surface coverage, and $K_{\text {ads }}$ is the adsorption equilibrium constant. Figure 3 represents the adsorption plot of

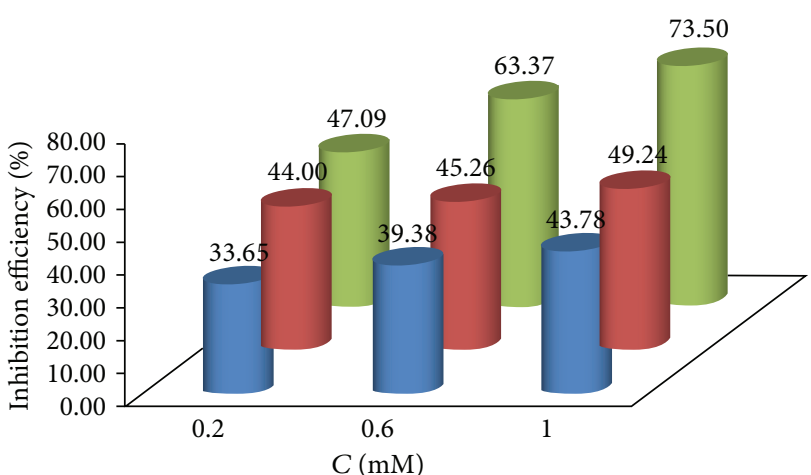

$$
\begin{aligned}
& \text { - Parent amine } \\
& \text { - Parent ketone } \\
& \text { - Schiff base }
\end{aligned}
$$

FIgURE 2: Comparison of inhibition efficiency of Schiff base, parent ketone, and parent amine in $1 \mathrm{M} \mathrm{HCl}$ at $24 \mathrm{~h}$.

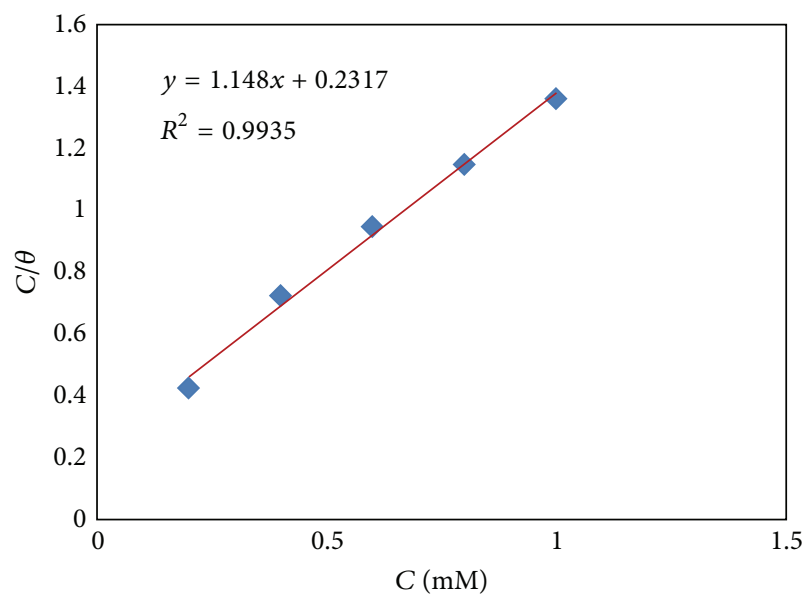

FIGURE 3: Langmuir adsorption isotherm for adsorption of A9Y5GPA on CS surface in $1 \mathrm{M} \mathrm{HCl}$ at $30^{\circ} \mathrm{C}$ for $24 \mathrm{~h}$.

A9Y5GPA obtained by the weight loss measurements of CS steel specimens in $1 \mathrm{M} \mathrm{HCl}$ at $30^{\circ} \mathrm{C}$ for $24 \mathrm{~h}$.

The value of adsorption equilibrium constant $K_{\text {ads }}$ is 4316 and is related to the standard free energy of adsorption $\Delta G_{\text {ads }}^{0}$ :

$$
\Delta G_{\mathrm{ads}}^{0}=-R T \ln \left(55.5 K_{\mathrm{ads}}\right),
$$

where 55.5 is the molar concentration of water, $R$ is the universal gas constant, and $T$ is the temperature in Kelvin [18]. $\Delta G_{\text {ads }}^{0}$ for A9Y5GPA on CS showed negative values indicating the spontaneity of the process. The value of $\Delta G_{\text {ads }}^{0}$ up to $-20 \mathrm{~kJ} \mathrm{~mol}^{-1}$ is an indication of the electrostatic interaction of the charged molecule, and the charged surface of the metal (physisorption) while $\Delta G_{\text {ads }}^{0}$ is more negative than $-40 \mathrm{~kJ}$ implies that inhibitor molecules are adsorbed strongly on the metal surface through coordinate-type bond (chemisorption) $[19,20]$. In the present investigation, the inhibitor molecules showed $\Delta G_{\text {ads }}^{0}-31.16 \mathrm{~kJ} / \mathrm{mol}$ for CS specimens, suggesting that the adsorption of inhibitor involves both electrostatic and chemical interactions. 


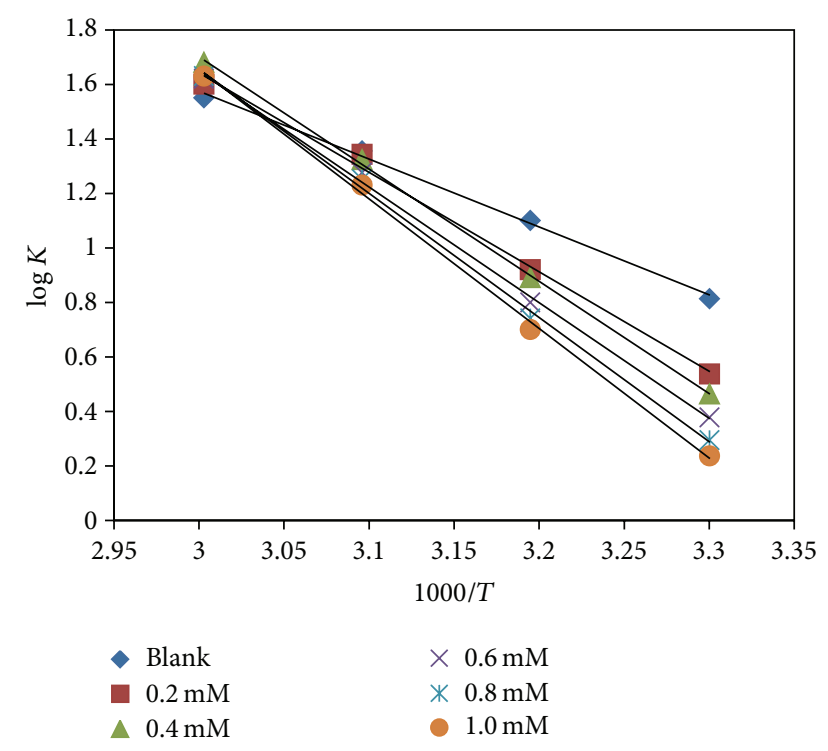

FIgURE 4: Arrhenius plots to calculate the activation energy of corrosion of CS in the absence and presence of A9Y5GPA.

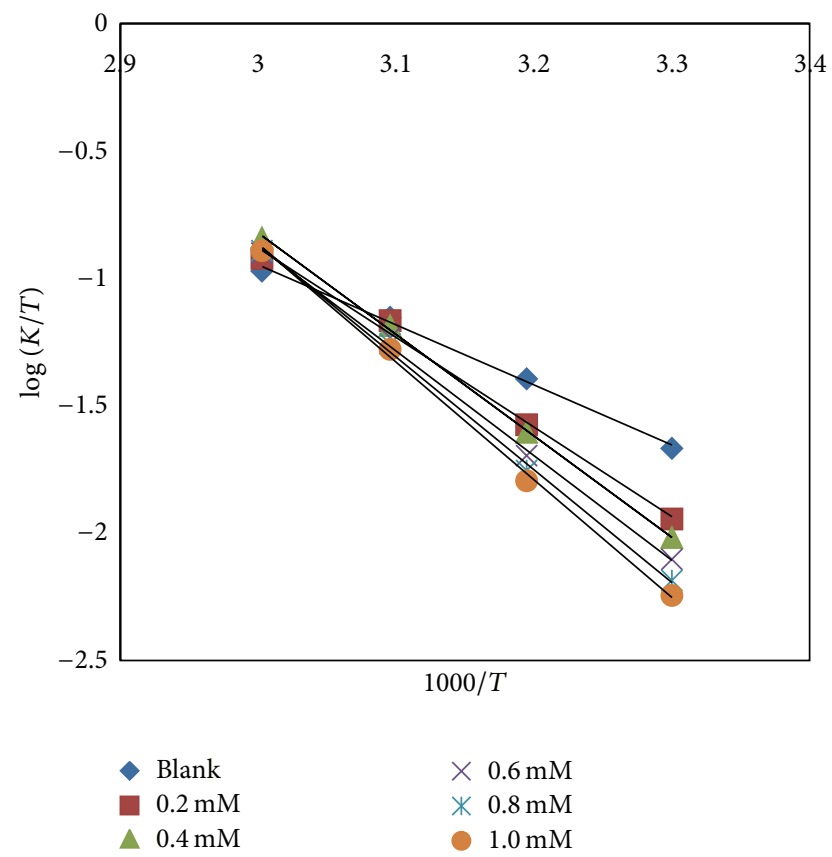

FIGURE 5: Plots of $\log (K / T)$ versus $1000 / T$ for the corrosion of CS in the absence and presence of A9Y5GPA.

3.4. Effect of Temperature. The effect of temperature on corrosion was also evaluated using weight loss measurement in the temperature range of $30-60^{\circ} \mathrm{C}$. The activation energy of corrosion with and without the inhibitor could be calculated by the Arrhenius equation:

$$
K=A \exp \left(-\frac{E_{a}}{R T}\right),
$$

where $K$ is the rate of corrosion, $E_{a}$ is the activation energy, $A$ is the frequency factor, $T$ is the temperature in Kelvin
TABLE 2: Thermodynamic parameters of corrosion of CS in $1 \mathrm{M} \mathrm{HCl}$ with and without the inhibitor A9Y5GPA.

\begin{tabular}{lcccc}
\hline$C(\mathrm{mM})$ & $\begin{array}{c}E_{a} \\
\left.(\mathrm{~kJ} \mathrm{~mol})^{-1}\right)\end{array}$ & $A$ & $\begin{array}{c}\Delta H^{*} \\
\left(\mathrm{~kJ} \mathrm{~mol}^{-1}\right)\end{array}$ & $\begin{array}{c}\Delta S^{*} \\
\left(\mathrm{~J} \mathrm{~mol}^{-1} \mathrm{~K}^{-1}\right)\end{array}$ \\
\hline Blank & 47.73 & $1.1 \times 10^{9}$ & 45.09 & -80.44 \\
0.2 & 69.89 & $3.9 \times 10^{12}$ & 67.24 & -12.68 \\
0.4 & 78.90 & $1.2 \times 10^{14}$ & 76.24 & 15.47 \\
0.6 & 81.29 & $2.4 \times 10^{14}$ & 78.63 & 21.64 \\
0.8 & 87.31 & $2.2 \times 10^{15}$ & 84.64 & 39.83 \\
1.0 & 91.02 & $8.2 \times 10^{15}$ & 88.36 & 50.95 \\
\hline
\end{tabular}

scale, and $R$ is the gas constant. Linear plots between $\log K$ and $1000 / T$ (Figure 4) having regression coefficients close to unity indicate that the corrosion of $\mathrm{CS}$ in $\mathrm{HCl}$ could be explained by the simple kinetic model. Enthalpy and entropy of activation $\left(\Delta H^{*}, \Delta S^{*}\right)$ were calculated from the transition state theory [21]:

$$
K=\left(\frac{R T}{N h}\right) \exp \left(\frac{\Delta S^{*}}{R}\right) \exp \left(\frac{-\Delta H^{*}}{R T}\right),
$$

where $N$ is the Avogadro number and $h$ is the Planks constant. A plot of $\log (K / T)$ versus $1000 / T$ gave straight lines for the corrosion of $\mathrm{CS}$ in $1 \mathrm{M} \mathrm{HCl}$ in the presence and absence of the inhibitor (Figure 5). Table 2 shows the activation energy and thermodynamic parameters of corrosion of $\mathrm{CS}$ in $1 \mathrm{MHCl}$ with and without the inhibitor A9Y5GPA. Activation energy of dissolution of the metal increased with the inhibitor concentration. This implies that the reluctance of dissolution of metal was increased with the inhibitor concentration. Positive signs of enthalpies with a regular rise reflect the endothermic nature of dissolution and the increasing difficulty of corrosion with the inhibitor. It is evident from Table 2 that the entropy of activation increases with the inhibitor concentration. For the blank and $0.2 \mathrm{mM}$ concentration of the inhibitor, the entropy of activation is large and negative. This implies that, in the rate determining step, a decrease in disordering takes place on going from reactants to the activated complex, and the activated molecules were in higher order state than that at the initial state. But as the concentration of inhibitor rises, the disordering of activated complex rises and the entropy of activation acquires positive values.

3.5. EIS Measurements. The corrosion response of CS in $1 \mathrm{M} \mathrm{HCl}$ in the presence of various concentrations of inhibitor has been investigated using electrochemical impedance spectroscopy at $30^{\circ} \mathrm{C}$. Figures $6(\mathrm{a})$ and $6(\mathrm{~b})$ represent the Nyquist plots and the Bode plots, respectively for CS specimens in $1 \mathrm{MHCl}$ in the presence of various concentrations of inhibitor. It is evident from the plots that the impedance response of metal specimens has marked difference in the presence and absence of the inhibitor A9Y5GPA.

Impedance behavior can be well explained by pure electric models that could verify and enable the calculation of numerical values corresponding to the physical and chemical properties of electrochemical system under examination [22]. 


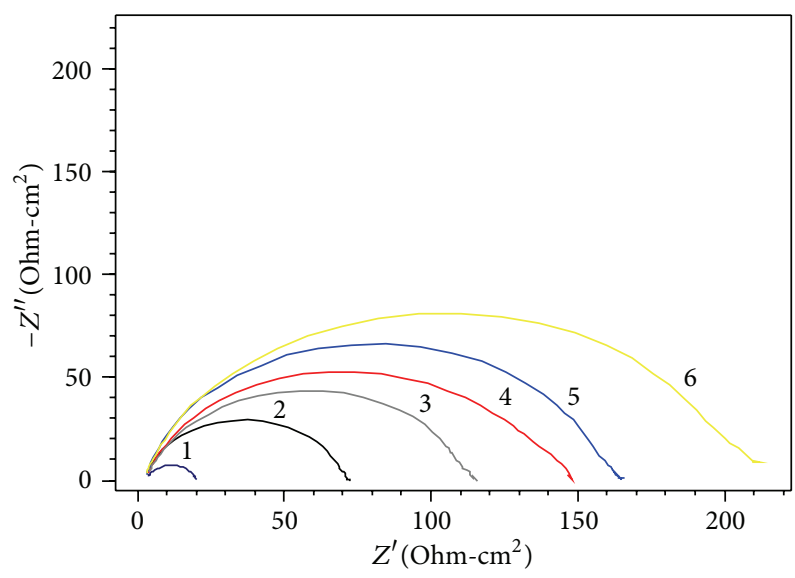

1. Blank
2. $0.2 \mathrm{mM}$
3. $0.4 \mathrm{mM}$
4. $0.6 \mathrm{mM}$

5. $0.8 \mathrm{mM}$

6. $1.0 \mathrm{mM}$

(a)

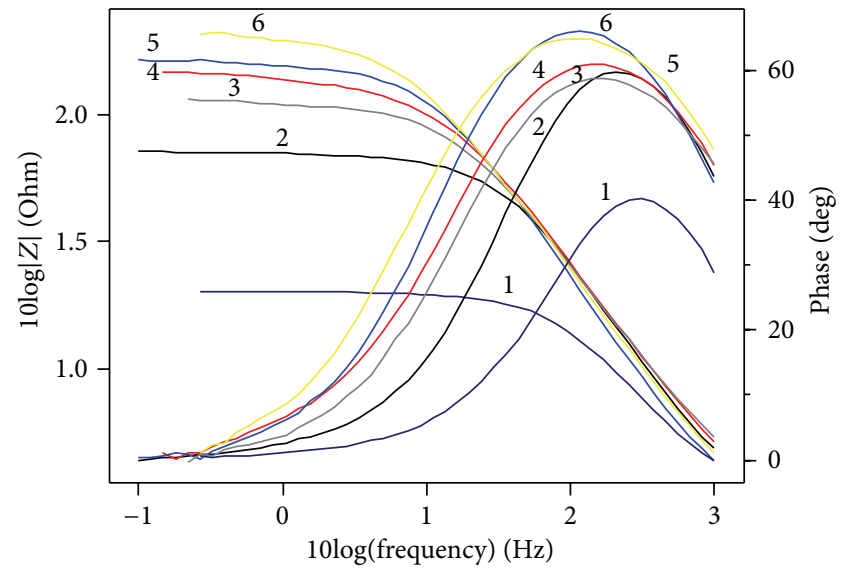
1. Blank
4. $0.6 \mathrm{mM}$
2. $0.2 \mathrm{mM}$
5. $0.8 \mathrm{mM}$
3. $0.4 \mathrm{mM}$
6. $1.0 \mathrm{mM}$

Figure 6: (a) Nyquist plots and (b) Bode plots for CS specimens in $1 \mathrm{M} \mathrm{HCl}$.

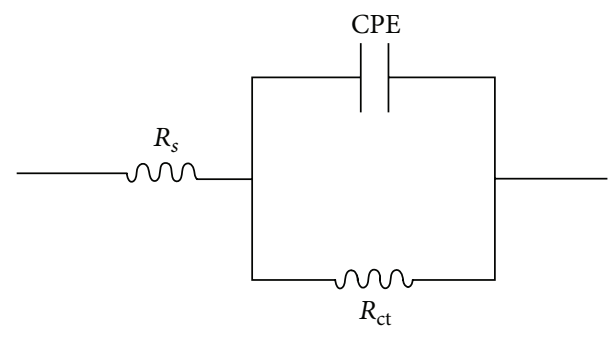

FIgURE 7: Equivalent circuit fitting for EIS measurements.

The simple equivalent circuit that fits to many electrochemical systems is composed of a double-layer capacitance, $R_{s}$ and $R_{\text {ct }}[23,24]$. To reduce the effects due to surface irregularities of metal, constant phase element (CPE) is introduced into the circuit instead of a pure double-layer capacitance which gives more accurate fit [25] as shown in Figure 7.

The impedance of CPE can be expressed as

$$
Z_{\mathrm{CPE}}=\frac{1}{Y_{0}(j \omega)^{n}},
$$

where $Y_{0}$ is the magnitude of CPE, $n$ is the exponent (phase shift), $\omega$ is the angular frequency, and $j$ is the imaginary unit. CPE may be resistance, capacitance, and inductance depending upon the values of $n$ [26]. In all experiments, the observed value of $n$ ranges between 0.75 and 1.0, suggesting the capacitive response of CPE. The EIS parameters such as $R_{\mathrm{ct}}$, CPE, and the calculated values of percentage of inhibition $\left(\eta_{\text {EIS }} \%\right)$ of CS specimens are listed in Table 3.

From Table 3 , it is clear that $R_{\mathrm{ct}}$ values are increased with increasing inhibitor concentration. The capacitance value $C_{\mathrm{dl}}$ decreases with inhibitor concentration, and this decrease in $C_{\mathrm{dl}}$ may be explained on the basis that the double layer between the charged metal surface and the
TABLE 3: Electrochemical impedance parameters of CS specimens in $1 \mathrm{M} \mathrm{HCl}$ at $30^{\circ} \mathrm{C}$ in the absence and presence of inhibitor A9Y5GPA.

\begin{tabular}{lccc}
\hline$C(\mathrm{mM})$ & $R_{\mathrm{ct}}\left(\Omega \mathrm{cm}^{2}\right)$ & $C_{\mathrm{dl}}\left(\mu \mathrm{F} \mathrm{cm}^{-2}\right)$ & $\eta_{\mathrm{EIS}} \%$ \\
\hline 0 & 15.7 & 104 & - \\
0.2 & 64.2 & 93.3 & 75.55 \\
0.4 & 91.1 & 92.6 & 82.77 \\
0.6 & 128 & 69.9 & 87.73 \\
0.8 & 149 & 60.8 & 89.46 \\
1.0 & 188 & 59.8 & 91.65 \\
\hline
\end{tabular}

solution would act as an electrical capacitor. These results suggest that the A9Y5GPA molecules function by adsorption at the metal/solution interface [27]. A maximum of $91.65 \%$ inhibition efficiency could be achieved at an inhibitor concentration of $1 \mathrm{mM}$ for CS specimen.

3.6. Potentiodynamic Polarization Studies. Figures 8(a) and 8(b) represent potentiodynamic and linear polarization curves for CS specimens in $1 \mathrm{M} \mathrm{HCl}$ at $30^{\circ} \mathrm{C}$ for CS specimens in the presence of various concentrations of inhibitor (A9Y5GPA). Polarization parameters like corrosion current densities $\left(I_{\text {corr }}\right)$, corrosion potential $\left(E_{\text {corr }}\right)$, cathodic Tafel slope $\left(b_{c}\right)$, anodic Tafel slope $\left(b_{a}\right)$, and inhibition efficiency $\left(\eta_{\text {pol }} \%\right)$ and linear polarization parameters like polarization resistance $\left(R_{p}\right)$ and inhibition efficiency $\left(\eta_{R_{p}} \%\right)$ for CS specimens are listed in Table 4 . A marked decrease in the corrosion current density $\left(I_{\text {corr }}\right)$ was observed in the presence of inhibitor A9Y5GPA. The lowest value of $I_{\text {corr }}$ was noticed for the inhibitor solution of concentration $1 \mathrm{mM}$ which exhibited a maximum inhibition efficiency of $89.08 \%$. The data show that addition of the Schiff base to acid media affected both the cathodic and anodic parts of the curves; it may be assumed that the inhibitor molecules are adsorbed 


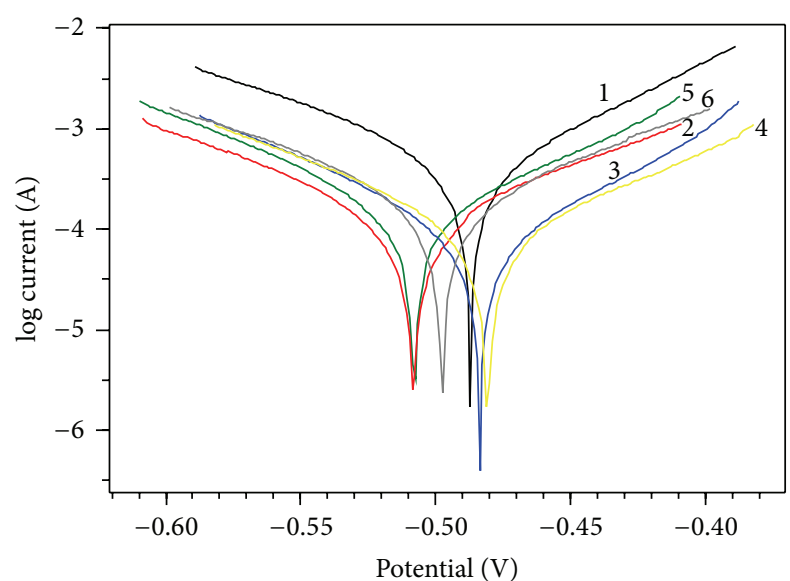

1. Blank
2. $0.2 \mathrm{mM}$
3. $0.4 \mathrm{mM}$
4. $0.6 \mathrm{mM}$
5. $0.8 \mathrm{mM}$
6. $1.0 \mathrm{mM}$

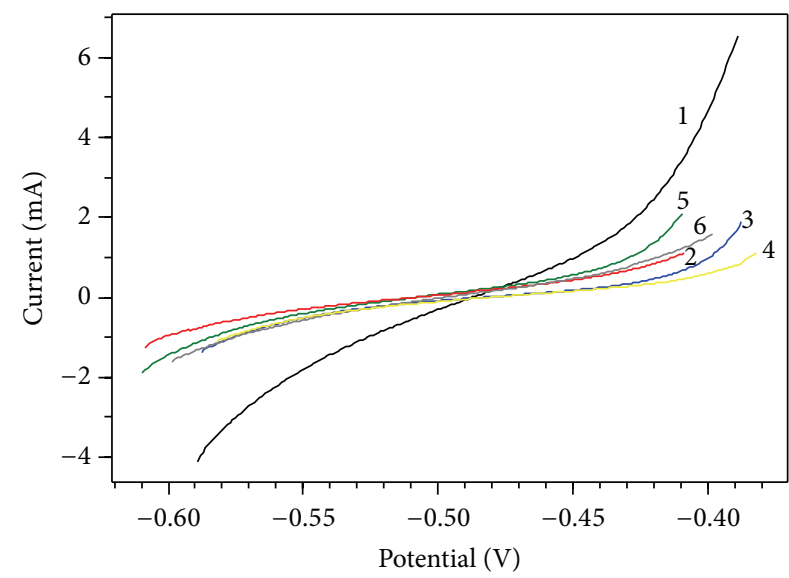
1. Blank
2. $0.2 \mathrm{mM}$
3. $0.4 \mathrm{mM}$

(a)

(b)

Figure 8: (a) Tafel plots and (b) linear polarization curves of CS specimens in $1 \mathrm{M} \mathrm{HCl}$ at $30^{\circ} \mathrm{C}$, with and without inhibitor.

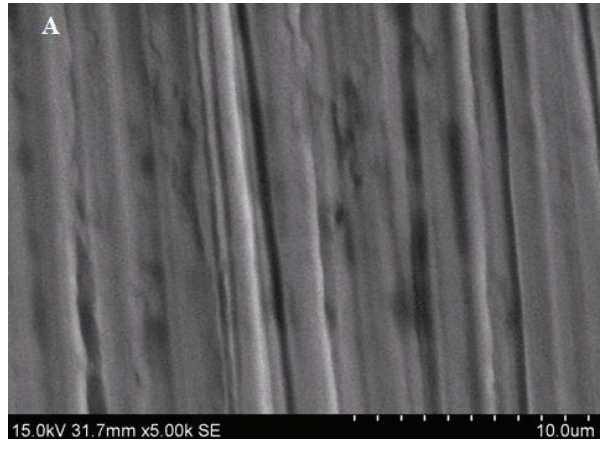

(a)

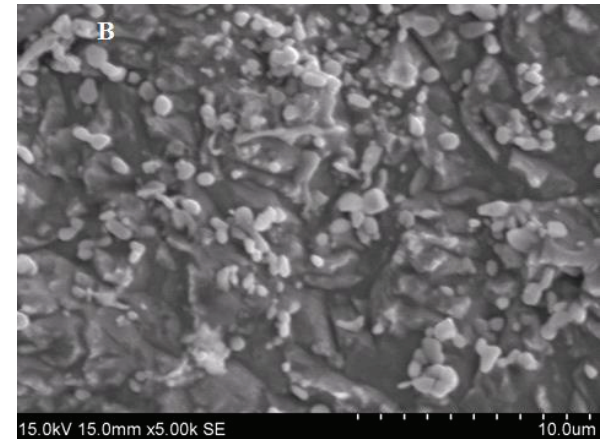

(b)

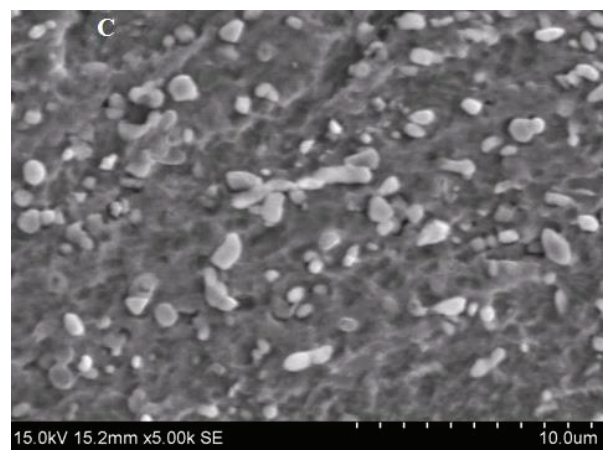

(c)

FIGURE 9: Scanning electron micrographs of carbon steel samples: (a) polished fresh specimens (b) immersed in $1 \mathrm{M} \mathrm{HCl} \mathrm{solution} \mathrm{for} 24 \mathrm{~h}$ and (c) immersed in $1 \mathrm{M} \mathrm{HCl}$ solution containing $1 \mathrm{mM}$ A9Y5GPA for $24 \mathrm{~h}$.

on anodic and cathodic sites uniformly. Generally, if the shift of $E_{\text {corr }}$ is $>85$ with respect to $E_{\text {corr }}$ of uninhibited solution, the inhibitor can be viewed as either cathodic or anodic type $[28,29]$. In the present study, the maximum shift of $E_{\text {corr }}$ is $21 \mathrm{mV}$, suggesting that A9Y5GPA acts as a mixed-type inhibitor for $\mathrm{CS}$ specimens in $1 \mathrm{M} \mathrm{HCl}$.
3.7. SEM Studies. The surface morphology of carbon steel surface was evaluated by scanning electron microscopy (SEM). Figures 9(a), 9(b), and 9(c) show the scanning electron micrographs of the bare carbon steel surface, CS specimens with and without inhibitor in hydrochloric acid medium, respectively. The morphology revealed that, in 
TABLE 4: Potentiodynamic and linear polarization parameters of CS specimens in $1 \mathrm{M} \mathrm{HCl}$ at $30^{\circ} \mathrm{C}$ in the absence and presence of A9Y5GPA.

\begin{tabular}{|c|c|c|c|c|c|c|c|}
\hline \multicolumn{5}{|c|}{ Tafel data } & \multicolumn{3}{|c|}{ Linear polarisation date } \\
\hline$C(\mathrm{mM})$ & $E_{\text {corr }}(\mathrm{mV} / \mathrm{SCE})$ & $I_{\text {corr }}\left(\mathrm{mA} / \mathrm{cm}^{2}\right)$ & $b_{a}(\mathrm{~V} / \mathrm{dec})$ & $-b_{c}(\mathrm{~V} / \mathrm{dec})$ & $\eta_{\mathrm{pol}} \%$ & $R_{p}(\mathrm{ohm})$ & $\eta_{R p} \%$ \\
\hline Blank & -489 & 0.6282 & 0.076 & 0.096 & - & 29.36 & - \\
\hline 0.2 & -495 & 0.1441 & 0.1 & 0.085 & 77.06 & 138.1 & 78.74 \\
\hline 0.4 & -505 & 0.1225 & 0.085 & 0.088 & 80.50 & 150.6 & 80.50 \\
\hline 0.6 & -510 & 0.106 & 0.093 & 0.098 & 83.13 & 192.7 & 84.76 \\
\hline 0.8 & -478 & 0.0793 & 0.083 & 0.089 & 87.38 & 225.0 & 86.95 \\
\hline 1.0 & -479 & 0.0686 & 0.088 & 0.087 & 89.08 & 244.3 & 87.98 \\
\hline
\end{tabular}
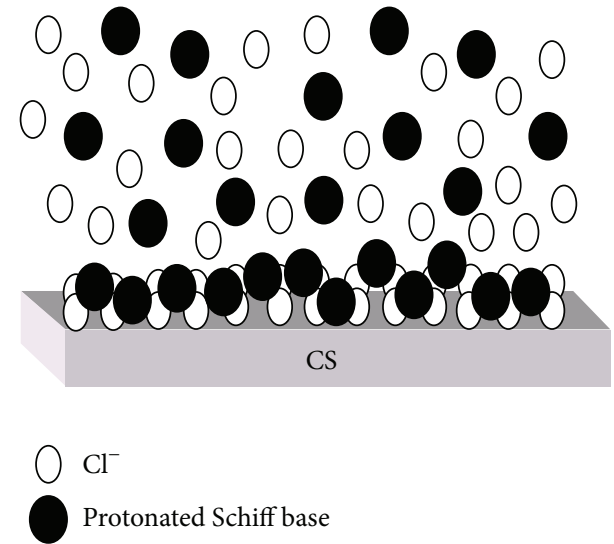

FIGURE 10: Schematic representation of mechanism of inhibition.

the absence of A9Y5GPA, the surface is highly corroded. However in the presence of inhibitor the rate of corrosion is suppressed. These observations suggest that the inhibitor forms a protective layer on the surface that prevents the attack of acid on the corroding metal CS.

3.8. Mechanism of Inhibition. It is well known that the surface of the metal is positively charged in acidic media [30]. It is believed that the $\mathrm{Cl}^{-}$ions could be specifically adsorbed on the metal surface and create an excess of negative charge on the surface. This will favour the adsorption of protonated Schiff base (A9Y5GPA ${ }^{+}$) on the surface [31] and hence reduce the dissolution of $\mathrm{Fe}$ to $\mathrm{Fe}^{2+}$ (Figure 10). Besides this electrostatic interaction between the protonated Schiff base and the metal surface, other possible interactions are (i) interaction of unshared electron pairs in the molecule with the metal, (ii) interaction of $\pi$-electrons with the metal, and (iii) a combination of types (i)-(ii) $[32,33]$. The $\pi$-electron cloud of the aromatic rings and the azomethine linkage also participate in the inhibition mechanism. Furthermore, the double bonds in the inhibitor molecule permit the back donation of metal d electrons to the $\pi^{*}$ orbital, and this type of interaction cannot occur with amines [34]. This can be justified by the lower inhibition efficiency of the parent amine than that of the Schiff base.

\section{Conclusions}

(1) A9Y5GPA acts as good inhibitor for CS in $1 \mathrm{M}$ hydrochloric acid medium.
(2) Inhibition efficiency increases with the increase in concentration of inhibitor.

(3) Compared to the parent amine and ketone, the Schiff base A9Y5GPA exhibited higher inhibition efficiency for CS.

(4) The inhibition mechanism is explained by adsorption. The adsorption of A9Y5GPA obeys the Langmuir adsorption isotherm.

(5) The thermodynamic parameters calculated from the adsorption isotherms showed that both physisorption and chemisorption are involved in the inhibition process.

\section{References}

[1] O. James, N. C. Oforka, and O. K. Abiola, "Inhibition of acid corrosion of mild steel by pyridoxal and pyridoxol hydrochlorides," International Journal of Electrochemical Science, vol. 2, pp. 278-284, 2007.

[2] S. A. Abd El-Maksoud, "The effect of organic compounds on the electrochemical behaviour of steel in acidic media. A review," International Journal of Electrochemical Science, vol. 3, pp. 528555, 2008.

[3] P. R. Vinod, T. K. Joby, K. S. Shaju, and P. Aby, "Corrosion inhibition investigations of 3- acetylpyridine semicarbazone on carbon steel in hydrochloric acid medium," Research on Chemical Intermediates, 2013.

[4] E. E. Ebenso, P. C. Okafor, O. E. Offiong, B. I. Ita, U. J. Ibok, and U. J. Ekpe, "Comparative investigation into the kinetics of corrosion inhibition of aluminium alloy AA 1060 in acidic medium," Bulletin of Electrochemistry, vol. 17, no. 10, pp. 459464, 2001.

[5] T. A. Sethi, R. K. Chaturvedi, Upadyay, and S. P. Marthur, "Corrosion inhibitory effects of some Schiff's bases on mild steel in acid media," Journal of the Chilean Chemical Society, vol. 52, pp. 1206-1213, 2007.

[6] K. P. Srivastva, A. Kumar, and R. Singh, "Bivalent transition metal complexes of tridentate Schiff base ligands: an ecofriendly study," Journal of Chemical and Pharmaceutical Research, vol. 2, pp. 68-77, 2010.

[7] S. B. Ade, M. N. Deshpande, and D. G. Kolhatkar, "Corrosion a universal environmental problem: a role of schiff base metal complexes as inhibitors," Journal of Chemical and Pharmaceutical Research, vol. 4, no. 2, pp. 1033-1035, 2012.

[8] P. Aby, T. K. Joby, P. R. Vinod, and K. S. Shaju, "Electrochemical and gravimetric corrosion inhibition investigations of a heterocyclic Schiff base derived from 3-formylindole," IOSR Journal of Applied Chemistry, vol. 1, pp. 17-23, 2012. 
[9] S. Deng, X. Li, and H. Fu, "Alizarin violet $3 \mathrm{~B}$ as a novel corrosion inhibitor for steel in $\mathrm{HCl}, \mathrm{H}_{2} \mathrm{SO}_{4}$ solutions," Corrosion Science, vol. 53, no. 11, pp. 3596-3602, 2011.

[10] X. Li, S. Deng, and H. Fu, "Blue tetrazolium as a novel corrosion inhibitor for cold rolled steel in sulfuric acid solution," Materials Chemistry and Physics, vol. 129, no. 3, pp. 696-700, 2011.

[11] K. S. Shaju, T. K. Joby, P. R. Vinod, and P. Aby, "Synergistic effect of KI on corrosion inhibition of mild steel by polynuclear Schiff base in sulphuric acid," ISRN Corrosion, vol. 2012, Article ID 425878, 8 pages, 2012.

[12] ASTM, "standard recommended practice for the laboratory immersion corrosion testing of metals," ASTM G-31-72, ASTM, Philadelphia, Pa, USA, 1990.

[13] K. C. Emregül and O. Atakol, "Corrosion inhibition of iron in $1 \mathrm{M} \mathrm{HCl}$ solution with Schiff base compounds and derivatives," Materials Chemistry and Physics, vol. 83, no. 2-3, pp. 373-379, 2004.

[14] A. Raman and P. Labine, Reviews on Corrosion Inhibitor Science and Technology, NACE, Houston, Tex, USA, 1986.

[15] H. Ashassi-Sorkhabi, B. Shaabani, and D. Seifzadeh, "Effect of some pyrimidinic Shciff bases on the corrosion of mild steel in hydrochloric acid solution," Electrochimica Acta, vol. 50, no. 1617, pp. 3446-3452, 2005.

[16] L. Elkadi, B. Mernari, M. Traisnel, F. Bentiss, and M. Lagrenée, "The inhibition action of 3,6-bis(2-methoxyphenyl)1,2-dihydro-1,2,4,5-tetrazine on the corrosion of mild steel in acidic media," Corrosion Science, vol. 42, no. 4, pp. 703-719, 2000.

[17] M. Bouklah, B. Hammouti, M. Lagrenée, and F. Bentiss, "Thermodynamic properties of 2,5-bis(4-methoxyphenyl)1,3,4-oxadiazole as a corrosion inhibitor for mild steel in normal sulfuric acid medium," Corrosion Science, vol. 48, no. 9, pp. 2831-2842, 2006.

[18] E. Cano, J. L. Polo, A. L. A. Iglesia, and J. M. Bastidas, "A study on the adsorption of benzotriazole on copper in hydrochloric acid using the inflection point of the isotherm," Adsorption, vol. 10, no. 3, pp. 219-225, 2004.

[19] F. Bentiss, M. Lebrini, and M. Lagrenée, “Thermodynamic characterization of metal dissolution and inhibitor adsorption processes in mild steel/2,5-bis(n-thienyl)-1,3,4-thiadiazoles/ hydrochloric acid system," Corrosion Science, vol. 47, no. 12, pp. 2915-2931, 2005.

[20] W.-H. Li, Q. He, S.-T. Zhang, C.-L. Pei, and B.-R. Hou, "Some new triazole derivatives as inhibitors for mild steel corrosion in acidic medium," Journal of Applied Electrochemistry, vol. 38, no. 3, pp. 289-295, 2008.

[21] M. Bouklah, N. Benchat, B. Hammouti, A. Aouniti, and S. Kertit, "Thermodynamic characterisation of steel corrosion and inhibitor adsorption of pyridazine compounds in $0.5 \mathrm{M} \mathrm{H}_{2} \mathrm{SO}_{4}$," Materials Letters, vol. 60, no. 15, pp. 1901-1905, 2006.

[22] A. R. Sathiya Priya, V. S. Muralidharam, and A. Subramannia, "Development of novel acidizing inhibitors for carbon steel corrosion in $15 \%$ boiling hydrochloric acid," Corrosion, vol. 64 , pp. 541-552, 2008.

[23] M. El Azhar, B. Mernari, M. Traisnel, F. Bentiss, and M. Lagrenée, "Corrosion inhibition of mild steel by the new class of inhibitors [2,5-bis(n-pyridyl)-1,3,4-thiadiazoles] in acidic media," Corrosion Science, vol. 43, no. 12, pp. 2229-2238, 2001.

[24] A. Yurt, A. Balaban, S. U. Kandemir, G. Bereket, and B. Erk, "Investigation on some Schiff bases as $\mathrm{HCl}$ corrosion inhibitors for carbon steel," Materials Chemistry and Physics, vol. 85, no. 2-3, pp. 420-426, 2004.
[25] J. R. Macdonald, Theory in Impedance Spectroscopy, John Wiley \& Sons, New York, NY, USA, 1987, edited by W. B. Johnson and J. R. Macdonald.

[26] A. K. Singh, S. K. Shukla, M. Singh, and M. A. Quraishi, "Inhibitive effect of ceftazidime on corrosion of mild steel in hydrochloric acid solution," Materials Chemistry and Physics, vol. 129, no. 1-2, pp. 68-76, 2011.

[27] M. MaCafferty and N. Hackerman, "Double layer capacitance of iron and corrosion inhibition with polymethylene diamines," Journal of the Electrochemical Society, vol. 119, pp. 146-154, 1972.

[28] X. Li, S. Deng, and H. Fu, "Synergism between red tetrazolium and uracil on the corrosion of cold rolled steel in $\mathrm{H}_{2} \mathrm{SO}_{4}$ solution," Corrosion Science, vol. 51, no. 6, pp. 1344-1355, 2009.

[29] E. S. Ferreira, C. Giacomelli, F. C. Giacomelli, and A. Spinelli, "Evaluation of the inhibitor effect of L-ascorbic acid on the corrosion of mild steel," Materials Chemistry and Physics, vol. 83, no. 1, pp. 129-134, 2004.

[30] Q. Qu, Z. Hao, S. Jiang, L. Li, and W. Bai, "Synergistic inhibition between dodecylamine and potassium iodide on the corrosion of cold rolled steel in $0.1 \mathrm{M}$ phosphoric acid," Materials and Corrosion, vol. 59, no. 11, pp. 883-888, 2008.

[31] F. Bentiss, M. Traisnel, and M. Lagrenee, "The substituted 1,3,4oxadiazoles: a new class of corrosion inhibitors of mild steel in acidic media," Corrosion Science, vol. 42, no. 1, pp. 127-146, 2000.

[32] D. Paul Schweinsberg, G. A. George, A. K. Nanayakkara, and D. A. Steinert, "The protective action of epoxy resins and curing agents-inhibitive effects on the aqueous acid corrosion of iron and steel," Corrosion Science, vol. 28, no. 1, pp. 33-42, 1988.

[33] H. Shokry, M. Yuasa, I. Sekine, R. M. Issa, H. Y. El-Baradie, and G. K. Gomma, "Corrosion inhibition of mild steel by Schiff base compounds in various aqueous solutions: part 1," Corrosion Science, vol. 40, no. 12, pp. 2173-2186, 1998.

[34] A. K. Singh and M. A. Quraishi, "Inhibiting effects of 5substituted isatin-based Mannich bases on the corrosion of mild steel in hydrochloric acid solution," Journal of Applied Electrochemistry, vol. 40, no. 7, pp. 1293-1306, 2010. 

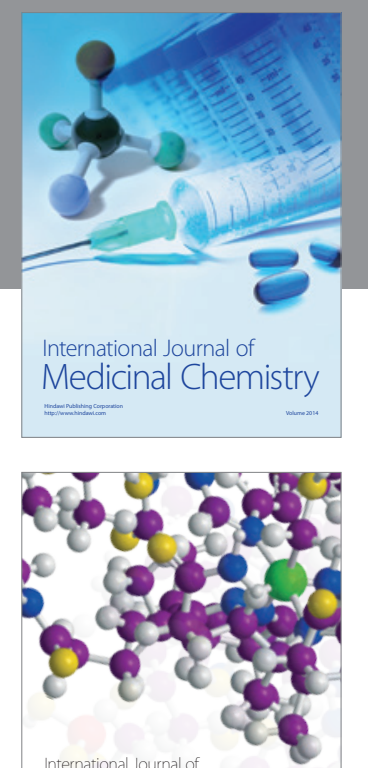

\section{Carbohydrate} Chemistry

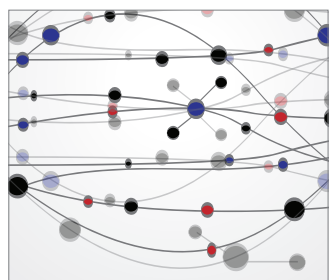

The Scientific World Journal
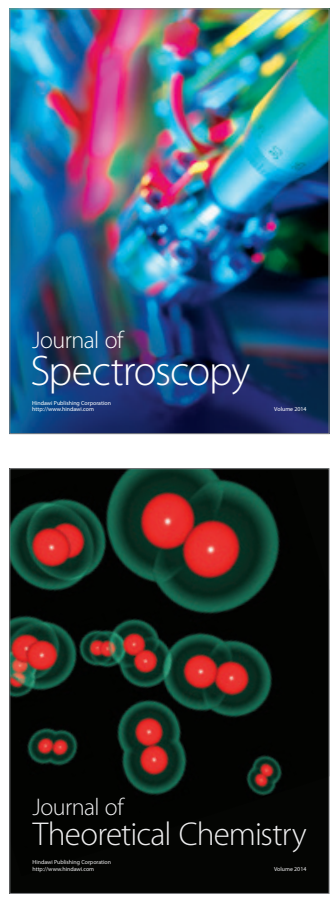
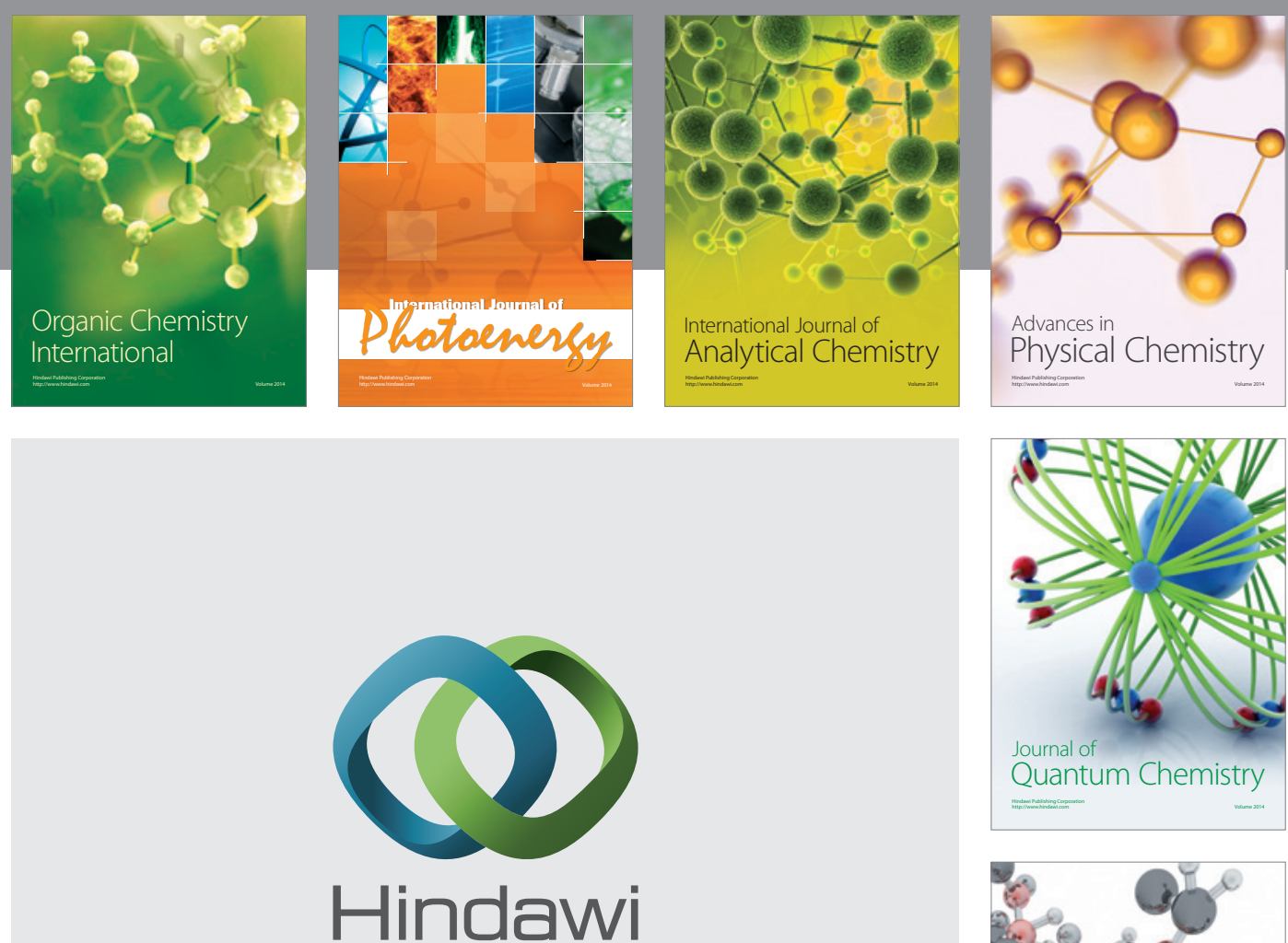

Submit your manuscripts at

http://www.hindawi.com

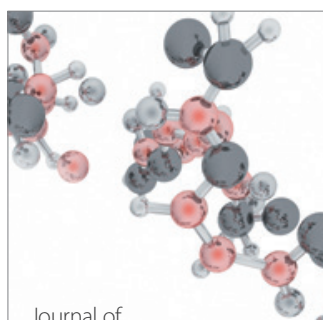

Analytical Methods

in Chemistry

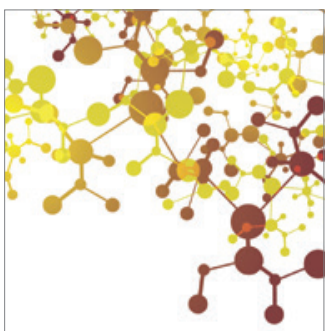

Journal of

Applied Chemistry

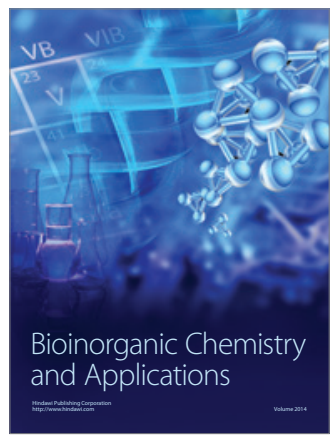

Inorganic Chemistry
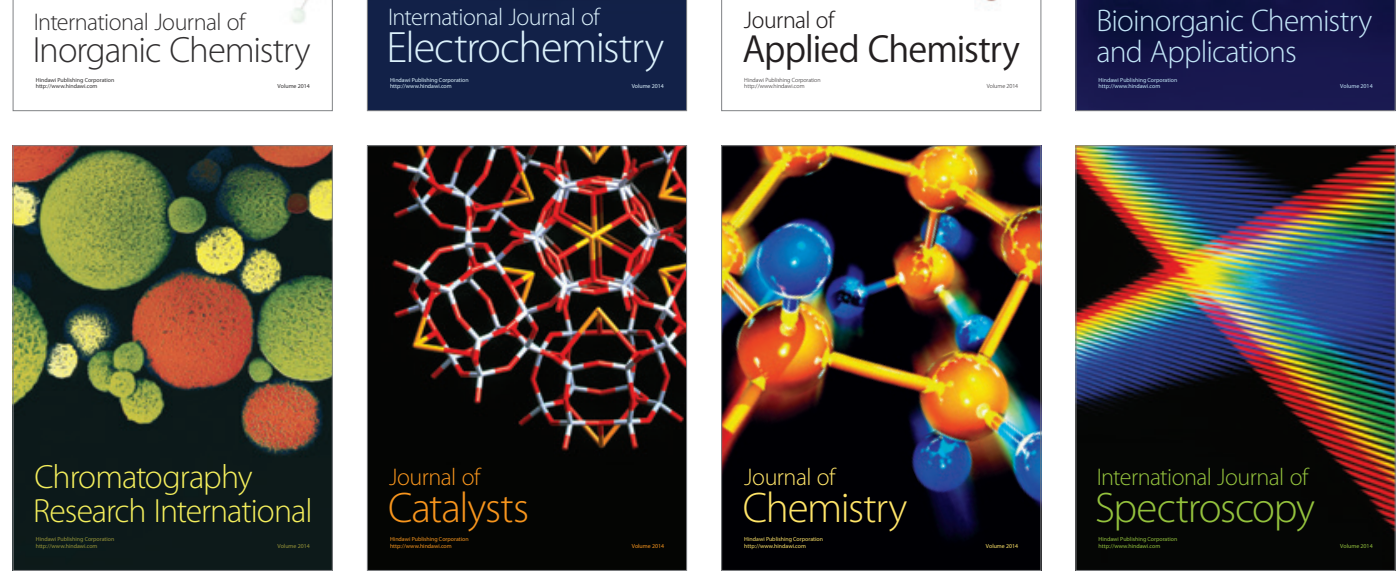